\title{
Short-term outcome of isolated lateral malleolar fracture treatment is independent of hospital trauma volume or teaching status: a nationwide retrospective cohort study
}

\author{
Malte Vehling ${ }^{1} \cdot$ Claudio Canal $^{1} \cdot$ Franziska Ziegenhain $^{1} \cdot$ Hans-Christoph Pape $^{1} \cdot$ Valentin Neuhaus $^{1}$ (I)
}

Received: 6 May 2021 / Accepted: 9 August 2021 / Published online: 16 August 2021

(c) The Author(s) 2021

\begin{abstract}
Introduction In light of current discussions about centralisation and teaching in medicine, we wanted to investigate the differences in in-hospital outcomes after surgical treatment of isolated ankle fractures, taking into account high-volume centres (HVCs) and low-volume centres (LVCs) and teaching procedures.

Methods A retrospective analysis of malleolar fractures recorded in a National Quality Assurance Database (AQC) from the period 01-01-1998 to 31-12-2018 was carried out. Inclusion criteria were isolated, and operatively treated lateral malleolar fractures (ICD-10 Code S82.6 and corresponding procedure codes). Variables were sought in bivariate and multivariate analyses. A total of 6760 cases were included. By dividing the total cases arbitrarily in half, $12 \mathrm{HVCs}(n=3327,49 \%)$ and 56 LVCs $(n=3433,51 \%)$ were identified.

Results Patients in HVCs were younger (48 vs. 50 years old), had more comorbidities (26\% vs. 19\%) and had more open fractures $(0.48 \%$ vs. $0.15 \%)$. Open reduction and internal fixation was the most common operative treatment at HVCs and LVCs (95\% vs. $98 \%)$. A more frequent use of external fixation (2.5\% vs. $0.55 \%)$ was reported at HVCs. There was no difference in mortality between treatment at HVCs and LVCs. A longer hospitalisation of $7.2 \pm 5$ days at HVCs vs. $6.3 \pm 4.8$ days at LVCs was observed. In addition, a higher rate of complications of $3.2 \%$ was found at HVCs compared to $1.9 \%$ at LVCs. The frequency of teaching operations was significantly higher at HVCs (30\% vs. 26\%). Teaching status had no influence on mortality or complications but was associated with a prolonged length of stay and operating time.

Conclusion We found significant differences between HVCs and LVCs in terms of in-hospital outcomes for ankle fractures. These differences could be explained due to a more severely ill patient population and more complex (also open) fracture patterns with resulting use of external fixation and longer duration of surgery. However, structural and organisational differences, such as an extended preoperative stays at HVCs and a higher teaching rate, were also apparent. No difference in mortality could be detected.
\end{abstract}

Keywords High-volume $\cdot$ Low-volume $\cdot$ Malleolar fracture $\cdot$ Orthopaedic trauma $\cdot$ Outcome

Valentin Neuhaus

Valentin.neuhaus@gmx.ch

Malte Vehling

maltevehling@googlemail.com

Claudio Canal

claudio.canal@usz.ch

Franziska Ziegenhain

franziska.ziegenhain@usz.ch

Hans-Christoph Pape

Hans-Christoph.Pape@usz.ch

1 Division of Trauma Surgery, Department of Traumatology, University Hospital Zurich, University of Zurich, Raemistrasse 100, CH-8091 Zurich, Switzerland

\section{Introduction}

Ankle fractures are common with an incidence of 122 to 187 per 100,000 population and account for the majority of foot and ankle injuries [1,2]. They account for $10-12 \%$ of all fractures $[3,4]$. Because of this high incidence, ankle fractures are not only a relevant medical topic but also one that requires attention from an economic point of view. Therefore, ankle fractures are ideal for research purposes.

Centralisation is already state of the art in highly specialised medical disciplines and has become entrenched by improving care and enhancing treatment outcomes [5]. Currently, there is both political and social debate about the need 
for centralisation in other areas of medical care [6-8]. This debate is being driven forward not only by medical aspects but also by economic and political considerations [9]. However, the implementation of centralisation and its extension to less highly specialised treatments has not yet been conclusively resolved in the medical community $[10,11]$. In this context, there is a lack of valid data to compare the outcome of malleolar fractures between high-volume centres (HVCs) and low-volume centres (LVCs). Apart from the aspect of centralisation, teaching has an important influence on outcome [12]. Treating ankle fractures is a standard teaching procedure for surgical residents due to the high incidence and standardised treatment.

The aim of this study was to compare in-hospital outcomes in terms of mortality, complication rate and length of stay (LOS) for a common injury with surgical treatment between HVCs and LVCs. The possible influence of teaching with the in-hospital outcome was also evaluated in this context.

\section{Methods}

\section{Study design and setting}

The national database of the Swiss Working Group for Quality Assurance in Surgery (Arbeitsgemeinschaft für Qualitätssicherung in der Chirurgie, AQC) was used for data collection. The AQC is an association for prospective data collection and scientific data analyses regarding surgical interventions and diseases. Membership and data entry is voluntary for surgical departments, however the Swiss Surgical Association gives a recommendation to use it. Since the AQC was established in 1995, more than 80 Swiss surgical departments have entered over 1.5 million cases into the database, this accounts for $85 \%$ of all Swiss surgical departments [13, 14]. The AQC database provides useful, prospective in-hospital data for scientific studies [15-17]. Using this database, a retrospective analysis of patients who suffered isolated lateral malleolar fractures between 1998 and 2018 was performed.

\section{Participants/Study subjects}

We included only patients with an isolated malleolar fracture who were treated operatively between 1998 and 2018. To identify these patients, we used the corresponding World Health Organization (WHO) International Classification of Disease Code (ICD-10) [18] S82.6 and the corresponding Schweizerische Operationsklassifikation procedure code (CHOP Code) [19] 79.36 with its subcategories. Additionally, a complete AQC form must have been available. These criteria were met by 6760 data sets after excluding 1813 patients due to incomplete AQC forms. In this study we used only anonymised data, therefore no additional ethical approval was required according to the local cantonal ethical review board (KEK, Zurich, Switzerland) [20]. Patients must however be informed and give general consent to enter their data prospectively into the AQC database.

\section{Variables, outcome measures and data sources}

During the study period, 69 surgical units provided data for patients with lateral malleolar fractures via the AQC system. The AQC data contain information on patient age and gender, specifications about the type of admission (registered/ planned or emergency), insurance status (private or statutory), length of hospital stay, time in the intensive care unit (ICU), concomitant injuries, American Society of Anesthesiologists (ASA) score (physical status classification system), comorbidities, need for reintubation and information about the discharge status (death, home, nursing home, senior residence, rehabilitation clinic and others). Moreover, the following procedural characteristics were available: fracture site (classified according to ICD-10 [18]); education level of the surgeon (divided into three groups-senior attending, junior attending (fellow) and residents); teaching status of the operation; procedure code (coded according to the CHOP code [19]) and duration of the surgery; other interventions; presence and severity of any perioperative complications (no complications, complications with conservative therapy, complications with surgical therapy, complications with long-term damage with conservative therapy and mortality); and the use of thromboembolism prophylaxis and antibiotics [12].

The hospitals providing data for this study were divided into two groups solely based on the number of ankle fracture cases treated surgically during the study period. By dividing the total cases arbitrarily in half, 12 HVCs ( $n=3327,49 \%$; HVC) and 56 LVCs ( $n=3433,51 \%$; LVC) were identified. Mortality, complication rates, and LOS were evaluated as outcome parameters. Independent variables were, among others, HVCs vs. LVCs and teaching status of the procedures. The definition of HVC/LVC is arbitrary-to minimize the grey zone for quantitative differences, we added a subanalysis: the highest 10\% ( 2 centres with 704 patients) and lowest 10\% (29 centres with 667 patients) were examined separately.

\section{Statistical analysis}

We extracted our data online from the AQC database using the evaluation tool AdjumedAnalyze (Adjumed Services AG, Zurich, Switzerland) and used the Statistical Package for Social Sciences (SPSS, version 24; IBM Corp., Armonk, NY, USA) for our statistical analysis. Chi-square, 
Mann-Whitney $U$ and Fisher tests were used where applicable for bivariate analysis. We found no normal distribution in our data based on a Kolmogorov-Smirnov test. Significant $(p<0.05)$ or nearly significant factors $(p<0.1)$ in bivariate analysis were chosen as potential risk factors for complications. These risk factors were evaluated as confounders in a stepwise backward likelihood logistic regression analysis. We performed only bivariate analysis with predictors for mortality due to the low number of deaths $(n=15)$. A $p$ value of $<0.05$ was considered statistically significant.

\section{Results}

\section{Demographics}

On average, 277 patients (209-382) were treated at HVCs, while 61 patients $(1-176)$ were treated at LVCs. Patients at HVCs were younger (48 vs. 50 years old), predominantly male ( $52 \%$ vs. $48 \%$ ), had a higher ASA category on average (ASA I $54 \%$ vs. $57 \%$, ASA II $41 \%$ vs. $37 \%$ ) and had more comorbidities (26\% at HVCs and $19 \%$ at LVCs). However, patients categorised as ASA III-V were more often treated at LVCs $(5.2 \%, 0.58 \%, 0.55 \%$ at LVCs vs. $4.1 \%, 0.06 \%, 0 \%$ at HVCs). The rate of emergency and planned admissions were similar between HVCs and LVCs. The rate of privately insured patients was higher at HVCs $(29 \%$ vs. $24 \%)$. A higher number of open fractures (oFx) were treated at HVCs ( $n=16,0.48 \%$ at HVCs vs. $n=5,0.15 \%$ at LVCs) (Table 1$)$.

\section{Treatment}

The most common surgical treatment was open reduction and internal fixation (ORIF) (96\%), followed by external fixation (1.5\%). ORIF was less frequently used at HVCs compared to LVCs (95\% vs. 98\%), while external fixation was more frequently used at HVCs $(2.5 \%$ vs. $0.55 \%)$. In the subgroup of oFx treatment, external fixation was more common (33\% in the oFx subgroup vs. $1.4 \%$ in the closed fracture (cFx) subgroup; $p<0.001)$. Duration of surgery was slightly longer at HVCs $(65 \pm 32 \mathrm{~min}$ at HVCs vs. $61 \pm 28 \mathrm{~min}$ at LVCs). Antibiotics were administered in most cases (89\%). The usage of prophylactic antibiotics was more common at HVCs (94\% at HVCs vs. 83\% at LVCs). All patients with an oFx received antibiotics (Table 2).

\section{Outcome}

Overall, the complication rate was $2.5 \%$ (3.2\% at HVCs vs. $1.9 \%$ at LVCs) (Table 1). We found an almost quadruple rate of complications in oFx compared to $\mathrm{cFx}(9.5 \%$ vs. $2.5 \% ; p=0.041)$. The most common complications were disturbance of wound healing, secondary dislocation, malpositioning of the implants, lesion to the nerve and hematoma. Predictors for complications were age, ASA III-IV, junior attending vs. senior attending, duration of surgery and hospital volume (Table 3). Preoperative LOS had no influence. On average, the LOS was $6.7 \pm 4.9$ days (7.2 \pm 5 days at HVCs and $6.3 \pm 4.8$ days at LVCs). A significantly longer pre- and postoperative stay was observed at HVCs. ICU stays were very rare, lasting $0.15 \pm 3.6 \mathrm{~h}$ when they did occur (even shorter duration at HVCs), and had no statistical significance (Table 1). A significantly longer hospital stay was noticed for the oFx subgroup $(15 \pm 6.9$ for the oFx subgroup vs. $6.7 \pm 4.9$ for the cFx subgroup, $p<0.001$ ). Most patients were discharged home (92\%), followed by discharge to a rehabilitation clinic $(2.7 \%)$, nursing home $(0.75 \%)$ or senior residence $(0.72 \%)$; this was similar for HVCs and LVCs. Fifteen patients died in hospital $(0.22 \%$; $0.15 \%$ at HVCs and $0.29 \%$ at LVCs) (Table 1).

\section{Teaching}

A total of $28 \%$ of the operations were performed as teaching procedures. The rate was significantly higher at HVCs (HVCs 30\% vs. LVCs 26\%) (Table 2). Teaching was not associated with a higher mortality rate $(0.16 \%$ in teaching yes vs. $0.047 \%$ in teaching no) or a higher complication rate ( $2.8 \%$ in teaching yes vs. $2.9 \%$ in teaching no). However, a significantly longer operation time $(68 \pm 29$ in teaching yes vs. $59 \pm 30$ in teaching no) and a prolonged LOS $(6.9 \pm 5$ in teaching yes vs. $6.2 \pm 4.7$ in teaching no) were observed (Table 4).

\section{Subgroup analysis}

Patients in the $10 \%$ highest volume centres were slightly older (50 vs. 48 years), sicker (33\% vs. $26 \%$ comorbidities), more often admitted as planned surgery ( $24 \%$ vs. $17 \%)$, more often operated by junior attendings ( $45 \%$ vs $40 \%$ ) as a teaching procedure (43\% vs. $30 \%$ ) within longer time of surgery (76 vs $65 \mathrm{~min}$ ) than in the other HVC. ORIF was the primary treatment in $90 \%$ (vs. 95\%). The length of stay and outcome were similar.

Patients in the $10 \%$ lowest volume centres were quite similar with the other LVC cohort.

The subgroup analysis of the top- $10 \%$ and low- $10 \%$ centres confirmed the results of the HVC vs. LVC evaluationexcept for age (Tables 5 and 6 ).

\section{Discussion}

With the ongoing political and socio-economic debate about medical infrastructure and the necessity of smaller clinics vs. the importance of the centralisation of medical specialties, 
Table 1 High-volume vs. lowvolume; patient characteristics

\begin{tabular}{|c|c|c|c|c|c|c|c|}
\hline \multirow[t]{2}{*}{ Parameter } & \multicolumn{2}{|c|}{ Total $(n=6760)$} & \multicolumn{2}{|c|}{ High-volume ( $n=3327)$} & \multicolumn{2}{|c|}{$\begin{array}{l}\text { Low-volume } \\
(n=3433)\end{array}$} & \multirow[t]{2}{*}{$p$ value } \\
\hline & $n$ & $\%$ & $n$ & $\%$ & $n$ & $\%$ & \\
\hline \multicolumn{8}{|l|}{ Age (years) } \\
\hline Mean \pm SD & $49 \pm 18$ & & $48 \pm 18$ & & $50 \pm 18$ & & $<0.001$ \\
\hline \multicolumn{8}{|l|}{ Gender } \\
\hline Male & 3392 & 50 & 1744 & 52 & 1648 & 48 & $<0.001$ \\
\hline Female & 3368 & 50 & 1583 & 48 & 1785 & 52 & \\
\hline \multicolumn{8}{|l|}{ ASA } \\
\hline I & 3767 & 56 & 1813 & 54 & 1954 & 57 & $<0.001$ \\
\hline II & 2640 & 39 & 1377 & 41 & 1263 & 37 & \\
\hline III & 312 & 4.6 & 135 & 4.1 & 177 & 5.2 & \\
\hline IV & 22 & 0.33 & 2 & 0.060 & 20 & 0.58 & \\
\hline $\mathrm{V}$ & 19 & 0.28 & 0 & 0 & 19 & 0.55 & \\
\hline \multicolumn{8}{|l|}{ Comorbidity } \\
\hline Yes & 1511 & 22 & 865 & 26 & 646 & 19 & $<0.001$ \\
\hline \multicolumn{8}{|l|}{ Admission type } \\
\hline Emergency & 5676 & 84 & 2776 & 83 & 2900 & 84 & n.s \\
\hline Registered, planned & 1084 & 16 & 551 & 17 & 533 & 16 & \\
\hline \multicolumn{8}{|l|}{ Insurance } \\
\hline Statutory & 4949 & 73 & 2349 & 71 & 2600 & 76 & $<0.001$ \\
\hline Private & 1811 & 27 & 978 & 29 & 833 & 24 & \\
\hline \multicolumn{8}{|l|}{ Open fracture } \\
\hline Yes & 21 & 0.31 & 16 & 0.48 & 5 & 0.15 & 0.013 \\
\hline \multicolumn{8}{|l|}{ Length of stay (days) } \\
\hline Mean \pm SD & $6.7 \pm 4.9$ & & $7.2 \pm 5.0$ & & $6.3 \pm 4.8$ & & $<0.001$ \\
\hline \multicolumn{8}{|c|}{ Length of stay preoperative (days) } \\
\hline Mean \pm SD & $1.8 \pm 2.3$ & & $2.2 \pm 2.4$ & & $1.5 \pm 2.2$ & & $<0.001$ \\
\hline \multicolumn{8}{|c|}{ Length of stay postoperative (days) } \\
\hline Mean \pm SD & $4.9 \pm 4.0$ & & $5.1 \pm 4.1$ & & $4.8 \pm 4.0$ & & $<0.001$ \\
\hline \multicolumn{8}{|l|}{ Duration ICU (hours) } \\
\hline Mean \pm SD & $0.15 \pm 3.6$ & & $0.078 \pm 1.6$ & & $0.22 \pm 4.7$ & & n.s \\
\hline \multicolumn{8}{|l|}{ Complications } \\
\hline Yes & 171 & 2.5 & 105 & 3.2 & 66 & 1.9 & 0.001 \\
\hline \multicolumn{8}{|l|}{ Discharge } \\
\hline Deceased & 15 & 0.22 & 5 & 0.15 & 10 & 0.29 & n.s \\
\hline At home & 6248 & 92 & 3091 & 93 & 3157 & 92 & \\
\hline Nursing home & 51 & 0.75 & 18 & 0.54 & 33 & 0.96 & \\
\hline Old people's home & 49 & 0.72 & 19 & 0.57 & 30 & 0.87 & \\
\hline Rehabilitation clinic & 185 & 2.7 & 82 & 2.5 & 103 & 3.0 & \\
\hline Other & 212 & 3.1 & 112 & 3.4 & 100 & 2.9 & \\
\hline
\end{tabular}

ASA American Society of Anesthesiologists Physical Status Classification, ICU Intensive Care Unit, $S D$ Standard Deviation

we took a closer look at the short-term in-hospital outcomes of isolated malleolar fractures in Swiss hospitals [8]. Ankle fractures are among the most common bone fractures in Switzerland [21, 22]. According to Schweizerische Unfallversicherungsanstalt (SUVA) statistics, the subcategory of lower leg, ankle and foot fractures accounts for roughly a third of the total cost of fracture management [21].
For this study, we collected data from the AQC data base for a 20-year period. The data was filtered based on ICD 10 and CHOP codes for isolated lateral malleolar fractures to compare the in-hospital outcome between HVCs and LVCs. We found significant differences in patient characteristics and short-term outcomes between the HVC group and the LVC group. 
Table 2 High-volume vs. Low-volume; procedure characteristics

\begin{tabular}{|c|c|c|c|c|c|c|c|}
\hline \multirow[t]{2}{*}{ Parameter } & \multicolumn{2}{|c|}{ Total $(n=6760)$} & \multicolumn{2}{|c|}{$\begin{array}{l}\text { High-volume } \\
(n=3327)\end{array}$} & \multicolumn{2}{|c|}{$\begin{array}{l}\text { Low-volume } \\
(n=3433)\end{array}$} & \multirow[t]{2}{*}{$p$ value } \\
\hline & $n$ & $\%$ & $n$ & $\%$ & $n$ & $\%$ & \\
\hline \multicolumn{8}{|l|}{ Surgeon class } \\
\hline Senior attending & 2603 & 39 & 983 & 30 & 1620 & 47 & \multirow[t]{3}{*}{$<0.001$} \\
\hline Junior attending & 2413 & 36 & 1345 & 40 & 1068 & 31 & \\
\hline Resident & 1744 & 26 & 999 & 30 & 745 & 22 & \\
\hline \multicolumn{8}{|l|}{ Type of surgery } \\
\hline ORIF & 6523 & 96 & 3146 & 95 & 3377 & 98 & \multirow[t]{7}{*}{$<0.001$} \\
\hline External fixator & 101 & 1.5 & 82 & 2.5 & 19 & 0.55 & \\
\hline Suture capsule or ligament & 51 & 0.75 & 43 & 1.3 & 8 & 0.23 & \\
\hline Hardware removal & 32 & 0.47 & 21 & 0.63 & 11 & 0.32 & \\
\hline $\mathrm{CR}$ & 34 & 0.50 & 24 & 0.72 & 10 & 0.29 & \\
\hline CRIF & 17 & 0.25 & 11 & 0.33 & 6 & 0.17 & \\
\hline Other reconstruction of the ankle joint & 2 & 0.030 & 0 & 0 & 2 & 0.058 & \\
\hline \multicolumn{8}{|l|}{ Duration surgery (minutes) } \\
\hline Mean \pm SD & \multicolumn{2}{|l|}{$63 \pm 30$} & \multicolumn{2}{|l|}{$65 \pm 32$} & \multicolumn{2}{|l|}{$61 \pm 28$} & $<0.001$ \\
\hline \multicolumn{8}{|l|}{ Teaching } \\
\hline Yes & 1897 & 28 & 996 & 30 & 901 & 26 & $<0.001$ \\
\hline \multicolumn{8}{|l|}{ Antibiotics } \\
\hline No antibiotics & 761 & 11 & 177 & 5.3 & 584 & 17 & \multirow[t]{3}{*}{$<0.001$} \\
\hline Prophylactic antibiotics (before start) & 5841 & 86 & 3054 & 92 & 2787 & 81 & \\
\hline Prophylactic antibiotics (after start) & 106 & 1.6 & 60 & 1.8 & 46 & 1.3 & \\
\hline
\end{tabular}

$C R$ Closed Reduction, IF Internal Fixation, OR Open Reduction, SD Standard Deviation

\begin{tabular}{|c|c|c|c|c|}
\hline & \multirow[t]{2}{*}{ Sig } & \multirow[t]{2}{*}{ OR } & \multicolumn{2}{|c|}{ 95\% C.I. for OR } \\
\hline & & & Lower & Upper \\
\hline Age & $<0.001$ & 1.021 & 1.011 & 1.031 \\
\hline ASA II (vs. I) & 0.963 & 0.992 & 0.699 & 1.408 \\
\hline ASA III (vs. I) & 0.021 & 1.953 & 1.108 & 3.444 \\
\hline ASA IV (vs. I) & $\mathbf{0 . 0 3 9}$ & 5.144 & 1.082 & 24.447 \\
\hline Junior attending (vs. senior attending) & 0.019 & 1.544 & 1.073 & 2.220 \\
\hline Resident (vs. senior attending) & 0.850 & 0.959 & 0.620 & 1.483 \\
\hline Duration surgery & $<0.001$ & 1.010 & 1.006 & 1.014 \\
\hline Prophylactic antibiotics (before start) (vs. no antibiotics) & 0.856 & 1.054 & 0.597 & 1.861 \\
\hline Prophylactic antibiotics (after start) (vs. no antibiotics) & 0.919 & 1.069 & 0.297 & 3.855 \\
\hline Antibiotic therapy (vs. no antibiotics) & $\mathbf{0 . 0 0 3}$ & 4.524 & 1.677 & 12.203 \\
\hline High-volume hospital (vs. low-volume) & 0.006 & 1.579 & 1.141 & 2.184 \\
\hline
\end{tabular}

Bold values indicate Statistically significant

ASA American Society of Anesthesiologists Physical Status Classification, C.I. confidence interval, $O R$ Odds Ratio
One strength of this study is the large sample size, which allowed controlling for different cofactors. Another strength is that the AQC databank provides prospective collected and standardised data. However, there are certain limitations. The de-identified patient information from the AQC only assesses in-hospital data and complications, missing relevant events after discharge. Furthermore the de-identified dataset made it impossible to re-check entered data, add missing relevant information. In addition, the data quality depends on the physician who input it and cannot be controlled. Moreover, due to anonymisation additional information about the treating hospital is not available. Also, the overestimation of biostatistical significance, easily reached due to the large sample size, 
Table 4 Teaching YES vs. NO

\begin{tabular}{|c|c|c|c|c|c|c|c|}
\hline \multirow[t]{2}{*}{ Parameter } & \multicolumn{2}{|c|}{ Total $(n=6760)$} & \multicolumn{2}{|c|}{$\begin{array}{l}\text { Teaching NO } \\
(n=2112)\end{array}$} & \multicolumn{2}{|c|}{$\begin{array}{l}\text { Teaching YES } \\
(n=1897)\end{array}$} & \multirow[t]{2}{*}{$p$ value } \\
\hline & $n$ & $\%$ & $n$ & $\%$ & $n$ & $\%$ & \\
\hline \multicolumn{8}{|l|}{ Age (years) } \\
\hline Mean \pm SD & $49 \pm 18$ & & $50 \pm 18$ & & $48 \pm 18$ & & $<0.001$ \\
\hline \multicolumn{8}{|l|}{ Gender } \\
\hline Male & 3392 & 50 & 1034 & 49 & 1013 & 53 & 0.005 \\
\hline Female & 3368 & 50 & 1078 & 51 & 884 & 47 & \\
\hline \multicolumn{8}{|l|}{ ASA } \\
\hline I & 3767 & 56 & 1121 & 53 & 1078 & 57 & 0.008 \\
\hline II & 2640 & 39 & 910 & 43 & 722 & 38 & \\
\hline III & 312 & 4.6 & 79 & 3.7 & 95 & 5.0 & \\
\hline IV & 22 & 0.33 & 2 & 0.095 & 1 & 0.053 & \\
\hline $\mathrm{V}$ & 19 & 0.28 & 0 & 0 & 1 & 0.053 & \\
\hline \multicolumn{8}{|l|}{ Comorbidity } \\
\hline Yes & 1511 & 22 & 503 & 24 & 408 & 22 & n.s \\
\hline \multicolumn{8}{|l|}{ Admission type } \\
\hline Emergency & 5676 & 84 & 1724 & 82 & 1579 & 83 & n.s \\
\hline $\begin{array}{l}\text { Registered, planned } \\
\text { Insurance }\end{array}$ & 1084 & 16 & 388 & 18 & 318 & 17 & \\
\hline Statutory & 4949 & 73 & 1340 & 63 & 1659 & 88 & $<0.001$ \\
\hline Private & 1811 & 27 & 772 & 37 & 238 & 13 & \\
\hline \multicolumn{8}{|l|}{ Length of stay (days) } \\
\hline Mean \pm SD & $6.7 \pm 4.9$ & & $6.2 \pm 4.7$ & & $6.9 \pm 5.0$ & & $<0.001$ \\
\hline \multicolumn{8}{|c|}{ Length of stay preoperative (days) } \\
\hline Mean \pm SD & $1.8 \pm 2.3$ & & $1.7 \pm 2.3$ & & $2.0 \pm 2.3$ & & $<0.001$ \\
\hline \multicolumn{8}{|c|}{ Length of stay postoperative (days) } \\
\hline Mean \pm SD & $4.9 \pm 4.0$ & & $4.6 \pm 3.8$ & & $4.9 \pm 4.0$ & & $<0.001$ \\
\hline \multicolumn{8}{|l|}{ Duration ICU (hours) } \\
\hline Mean \pm SD & $0.15 \pm 3.6$ & & $0.055 \pm 1.1$ & & $0.067 \pm 1.1$ & & n.s \\
\hline \multicolumn{8}{|l|}{ Complications } \\
\hline Yes & 171 & 2.5 & 62 & 2.9 & 54 & 2.8 & n.s \\
\hline \multicolumn{8}{|l|}{ Discharge } \\
\hline Deceased & 15 & 0.22 & 1 & 0.047 & 3 & 0.16 & n.s \\
\hline \multicolumn{8}{|c|}{ Duration surgery (minutes) } \\
\hline Mean \pm SD & $63 \pm 30$ & & $59 \pm 30$ & & $68 \pm 29$ & & $<0.001$ \\
\hline
\end{tabular}

ASA American Society of Anesthesiologists Physical Status Classification, ICU Intensive Care Unit, $S D$ Standard Deviation

is problematic and must be interpreted carefully in a clinical context.

Comparing HVCs and LVCs, the younger age of patients, the predominance of male patients and the more frequent use of external fixation in the HVC group could be seen as a consequence of the bipolar incidence of malleolar fractures, having a peak with young male patients mostly due to highenergy trauma and a second peak in elderly (mostly female) patients due to lower-energy trauma [3, 23]. This is also consistent with the higher rate of open fractures at HVCs.

Regarding the discrepancies in the in-hospital outcomes, patients at HVCs had a longer hospitalisation period and duration of surgery and a higher complication rate. The longer hospitalisation at HVCs with longer pre- and postoperative stays could be caused by a structurally induced delay at the HVCs (waiting lists for surgery) and the increased use of external fixation, which often necessitates a second procedure. The use of external fixation also indicates a potentially worse soft tissue condition and more complex fracture patterns due to the predicted high-energy trauma in the younger patient population. In particular, the associated soft tissue injury is a risk factor for longer hospitalisation and complications [24, 25]. A slightly shorter postoperative stay was noted in the top- $10 \%$ centres, despite the 
Table 5 High-volume vs. lowvolume; patient characteristics

\begin{tabular}{|c|c|c|c|c|c|c|c|}
\hline \multirow[t]{2}{*}{ Parameter } & \multicolumn{2}{|c|}{ Total $(n=6760)$} & \multicolumn{2}{|c|}{$\begin{array}{l}10 \% \text { High-volume } \\
(n=704)\end{array}$} & \multicolumn{2}{|c|}{$\begin{array}{l}10 \% \text { Low-volume } \\
(n=667)\end{array}$} & \multirow[t]{2}{*}{$p$ value } \\
\hline & $n$ & $\%$ & $n$ & $\%$ & $n$ & $\%$ & \\
\hline \multicolumn{8}{|l|}{ Age (years) } \\
\hline Mean \pm SD & $49 \pm 18$ & & $50 \pm 18$ & & $49 \pm 18$ & & 0.04 \\
\hline \multicolumn{8}{|l|}{ Gender } \\
\hline Male & 3392 & 50 & 392 & 56 & 317 & 48 & 0.003 \\
\hline Female & 3368 & 50 & 312 & 44 & 350 & 53 & \\
\hline \multicolumn{8}{|l|}{ ASA } \\
\hline $\mathrm{I}$ & 3767 & 56 & 440 & 63 & 414 & 62 & n.s \\
\hline II & 2640 & 39 & 235 & 33 & 222 & 33 & \\
\hline III & 312 & 4.6 & 29 & 4.1 & 30 & 4.5 & \\
\hline IV & 22 & 0.33 & 0 & 0 & 1 & 0.15 & \\
\hline $\mathrm{V}$ & 19 & 0.28 & 0 & 0 & 0 & 0 & \\
\hline \multicolumn{8}{|l|}{ Comorbidity } \\
\hline Yes & 1511 & 22 & 233 & 33 & 132 & 20 & 0.002 \\
\hline \multicolumn{8}{|l|}{ Admission type } \\
\hline Emergency & 5676 & 84 & 538 & 76 & 568 & 85 & $<0.001$ \\
\hline Registered, planned & 1084 & 16 & 166 & 24 & 99 & 15 & \\
\hline \multicolumn{8}{|l|}{ Insurance } \\
\hline Statutory & 4949 & 73 & 516 & 73 & 536 & 80 & 0.002 \\
\hline Private & 1811 & 27 & 188 & 27 & 131 & 20 & \\
\hline \multicolumn{8}{|l|}{ Open fracture } \\
\hline Yes & 21 & 0.31 & 7 & 0.13 & 2 & 0.30 & 0.01 \\
\hline \multicolumn{8}{|l|}{ Length of stay (days) } \\
\hline Mean \pm SD & $6.7 \pm 4.9$ & & $7.3 \pm 4.2$ & & $6.8 \pm 4.9$ & & 0.048 \\
\hline \multicolumn{8}{|c|}{ Length of stay preoperative (days) } \\
\hline Mean \pm SD & $1.8 \pm 2.3$ & & $2.4 \pm 2.4$ & & $1.4 \pm 2.2$ & & $<0.001$ \\
\hline \multicolumn{8}{|c|}{ Length of stay postoperative (days) } \\
\hline Mean \pm SD & $4.9 \pm 4.0$ & & $4.9 \pm 3.3$ & & $5.4 \pm 4.3$ & & 0.027 \\
\hline \multicolumn{8}{|l|}{ Duration ICU (hours) } \\
\hline Mean \pm SD & $0.15 \pm 3.6$ & & $0 \pm 0$ & & $0.0090 \pm 0.094$ & & 0.012 \\
\hline \multicolumn{8}{|l|}{ Complications } \\
\hline Yes & 171 & 2.5 & 24 & 3.4 & 10 & 1.5 & 0.023 \\
\hline \multicolumn{8}{|l|}{ Discharge } \\
\hline Deceased & 15 & 0.22 & 0 & 0 & 1 & 0.15 & $<0.001$ \\
\hline At home & 6248 & 92 & 603 & 86 & 618 & 93 & \\
\hline Nursing home & 51 & 0.75 & 7 & 0.99 & 2 & 0.30 & \\
\hline Old people's home & 49 & 0.72 & 1 & 0.14 & 5 & 0.75 & \\
\hline Rehabilitation clinic & 185 & 2.7 & 21 & 3.0 & 14 & 2.1 & \\
\hline Other & 212 & 3.1 & 72 & 10 & 27 & 4.0 & \\
\hline
\end{tabular}

ASA American Society of Anesthesiologists Physical Status Classification, ICU Intensive Care Unit, SD Standard Deviation more frequent use of external fixation. This might indicate, together with the lower rate of discharge to home, a tendency for very HVC to discharge patients to regional hospitals or geriatric clinics.

Furthermore the higher rate of privately insured patients in HVC could be a confounding factor, which was accounted for in multivariate analysis in our study population. Yet it has been found to be associated with higher complication rates in previous studies at a Swiss trauma centre [26].

Despite the difference in hospitalisation duration between HVCs and LVCs, the mean LOS ranks at the lower end of the described LOS in the literature [23, 27-31]. Regarding the differences in the LOS, a multicenter analysis from the Netherlands demonstrated longer hospitalisation at HVCs 
Table 6 High-volume vs. low-volume; procedure characteristics

\begin{tabular}{|c|c|c|c|c|c|c|c|}
\hline \multirow[t]{2}{*}{ Parameter } & \multicolumn{2}{|c|}{ Total $(n=6760)$} & \multicolumn{2}{|c|}{$\begin{array}{l}10 \% \text { high-vol- } \\
\text { ume }(n=704)\end{array}$} & \multicolumn{2}{|c|}{$\begin{array}{l}10 \% \text { low-vol- } \\
\text { ume }(n=667)\end{array}$} & \multirow[t]{2}{*}{$p$ value } \\
\hline & $n$ & $\%$ & $n$ & $\%$ & $n$ & $\%$ & \\
\hline \multicolumn{8}{|l|}{ Surgeon class } \\
\hline Senior attending & 2603 & 39 & 164 & 23 & 308 & 46 & \multirow[t]{3}{*}{$<0.001$} \\
\hline Junior attending & 2413 & 36 & 315 & 45 & 204 & 31 & \\
\hline Resident & 1744 & 26 & 225 & 32 & 155 & 23 & \\
\hline \multicolumn{8}{|l|}{ Type of surgery } \\
\hline ORIF & 6523 & 96 & 635 & 90 & 656 & 98 & \multirow[t]{7}{*}{$<0.001$} \\
\hline External fixator & 101 & 1.5 & 42 & 6.0 & 1 & 0.15 & \\
\hline Suture capsule or ligament & 51 & 0.75 & 5 & 0.71 & 6 & 0.90 & \\
\hline Hardware removal & 32 & 0.47 & 9 & 1.3 & 1 & 0.15 & \\
\hline $\mathrm{CR}$ & 34 & 0.50 & 6 & 0.85 & 1 & 0.15 & \\
\hline CRIF & 17 & 0.25 & 7 & 0.99 & 2 & 0.30 & \\
\hline Other reconstruction of the ankle joint & 2 & 0.030 & 0 & 0 & 0 & 0 & \\
\hline \multicolumn{8}{|l|}{ Duration surgery (minutes) } \\
\hline Mean \pm SD & \multicolumn{2}{|l|}{$63 \pm 30$} & \multicolumn{2}{|l|}{$76 \pm 37$} & \multicolumn{2}{|l|}{$66 \pm 31$} & $<0.001$ \\
\hline \multicolumn{8}{|l|}{ Teaching } \\
\hline Yes & 1897 & 28 & 305 & 43 & 167 & 25 & $<0.001$ \\
\hline \multicolumn{8}{|l|}{ Antibiotics } \\
\hline No antibiotics & 761 & 11 & 14 & 2.0 & 119 & 18 & \multirow[t]{3}{*}{$<0.001$} \\
\hline Prophylactic antibiotics (before start) & 5841 & 86 & 681 & 97 & 533 & 80 & \\
\hline Prophylactic antibiotics (after start) & 106 & 1.6 & 1 & 0 & 11 & 1.6 & \\
\hline
\end{tabular}

CR Closed Reduction, IF Internal Fixation, OR Open Reduction, SD Standard Deviation for fractures of the lower extremities. This was attributed in particular to the severity of the trauma (which is probably also the cause in our study) and the accompanying injuries [32]. Jain et al. showed a decreased LOS with higher surgeon case load for humerus fractures [33]. To the best of our knowledge, other data comparing the influence of hospital volume on LOS for other fractures is not available. For planned orthopedic procedures, such as hip and knee arthroplasty, there is a shorter LOS at HVCs and a higher case load per surgeon [34-38].

We found an overall complication rate of $2.5 \%$. The LVCs showed a complication rate of $1.9 \%$ compared to $3.2 \%$ for HVCs $(p=0.001)$. Nonetheless, these complication rates are at the lower end of the reported complication rates for malleolar fractures in the literature, ranging from 2-14\% [39-42] and even up to $26 \%$ in elderly subpopulations [43]. A higher mortality rate did not occur in this study. These discrepancies in in-hospital outcomes may be due to factors such as institutional differences, different patient characteristics, injury severity or the surgeon's experience. It should be noted that our data cover only in-hospital followup and therefore misses complications during the outpatient phase. Accuracy of data collection is also a factor. Some of these variables can be accounted for in our study but not all. At HVCs we observed a younger and predominantly male patient collective, which leads to the assumption of high-energy trauma as the cause of injury and more complex fracture patterns [23], resulting in a higher complication rate.

In general, teaching is a risk factor for a worse outcome. The significantly higher frequency of teaching operations at HVCs was associated with prolonged LOS, which is consistent with observations for teaching procedures in relation to hip fractures [12, 44] and general surgeries [45]. Otherwise, a large databank study of emergency and general surgeries found no difference in LOS between teaching and nonteaching surgeries [46].

Another acknowledged factor in extended hospitalisation seems to be the prevalence of comorbidities as an independent risk factor [47]. In our study, a higher prevalence of comorbidities in the HVC group was noticeable, as was a prolonged stay. Additionally, in a National Health Service (NHS) investigation of ankle fractures a prolonged stay was associated with the primary use of external fixation [29], which was five times more frequent at HVCs in our study.

The discussion regarding whether there is a difference in outcome between HVCs and LVCs has been evaluated for different surgical disciplines in the literature. Specifically for traumatology, three papers evaluated the outcomes at HVCs regarding the influence of caseload on clinical outcomes. In a single-center observation by Sava et al., the authors saw no change in mortality in relation to hip fractures based on the 
surgeon caseload [48]. Similarly, a meta-analysis by Wiegers et al. of hip fracture treatment at HVCs and LVCs found no significant difference in outcomes in general [49]. However, Marx et al. found caseload to be a significant predictor of in-hospital mortality [50]. Dumas et al. found evidence for other surgical disciplines and procedures. For example, they found advantageous outcomes of tracheotomies as small, routine, emergency procedures at HVCs [51]. Amato et al. found advantages for HVCs for 26 clinical areas, including hip fractures [52]. Regarding the situation in Switzerland, Mehra et al. found a preferable outcome and economic advantages in hospitals with higher structural care levels for femoral neck fractures. Correlating data for ankle fractures is currently not available.

\section{Conclusion}

There is no evidence regarding the influence of hospital volume on in-hospital mortality for patients with ankle fractures. Despite this, there is evidence of a prolonged LOS and a higher complication rate associated with treatment at HVCs for ankle fractures. Whether this is a function of the processes and treatment strategies or the underlying patient characteristics cannot be definitively answered. Teaching procedures were shown to be safe with no association with higher mortality or complication rates. However, further research is needed, particularly due to the high number of cases and the total cost.

Funding Open Access funding provided by Universität Zürich. The authors have no funding to declare.

\section{Declarations}

Conflict of interest There are no conflicts of interests to declare.

Ethical approval The data of this study bases on anonymized, de-identified data; our institutional review board waves the necessity from institutional review board approval.

Open Access This article is licensed under a Creative Commons Attribution 4.0 International License, which permits use, sharing, adaptation, distribution and reproduction in any medium or format, as long as you give appropriate credit to the original author(s) and the source, provide a link to the Creative Commons licence, and indicate if changes were made. The images or other third party material in this article are included in the article's Creative Commons licence, unless indicated otherwise in a credit line to the material. If material is not included in the article's Creative Commons licence and your intended use is not permitted by statutory regulation or exceeds the permitted use, you will need to obtain permission directly from the copyright holder. To view a copy of this licence, visit http://creativecommons.org/licenses/by/4.0/.

\section{References}

1. Melton LJ 3rd, Crowson CS, O'Fallon WM. Fracture incidence in Olmsted County, Minnesota: comparison of urban with rural rates and changes in urban rates over time. Osteoporos Int. 1999;9(1):29-37.

2. Court-Brown CM, McBirnie J, Wilson G. Adult ankle fracturesan increasing problem? Acta Orthop Scand. 2009;69(1):43-7.

3. Beerekamp MSH, de Muinck Keizer RJO, Schep NWL, Ubbink DT, Panneman MJM, Goslings JC. Epidemiology of extremity fractures in the Netherlands. Injury. 2017;48(7):1355-62.

4. Elsoe R, Ostgaard SE, Larsen P. Population-based epidemiology of 9767 ankle fractures. Foot Ankle Surg. 2018;24(1):34-9.

5. Learn PA, Bach PB. A decade of mortality reductions in major oncologic surgery: the impact of centralization and quality improvement. Med Care. 2010;48(12):1041-9.

6. Greiter M. Zentralisierung vor allem in der Deutschschweiz erwünscht [Available from: https://www.hplus.ch/de/zahlenstatistiken/h-spital-und-klinik-barometer/erwartungenansspital/ zentralisierungvoralleminderdeutschschweizerwuenscht/.

7. Böcken DJ (2019) Eine bessere Versorgung ist nur mit halb so vielen Kliniken möglich

8. Hehli S (2018) Die Schweiz hat viel zu viele Spitäler-mit diesen Rezepten könnte es besser werden. NZZ. 06.02.2018

9. Bhattarai N, McMeekin P, Price C, Vale L. Economic evaluations on centralisation of specialised healthcare services: a systematic review of methods. BMJ Open. 2016;6(5):e011214.

10. Vonlanthen R, Lodge P, Barkun JS, Farges O, Rogiers X, Soreide $\mathrm{K}$, et al. Toward a consensus on centralization in surgery. Ann Surg. 2018;268(5):712-24.

11. Kelly C, Hulme C, Farragher T, Clarke G. Are differences in travel time or distance to healthcare for adults in global north countries associated with an impact on health outcomes? A systematic review. BMJ Open. 2016;6(11):e013059.

12. Canal C, Kaserer A, Ciritsis B, Simmen HP, Neuhaus V, Pape HC. Is there an influence of surgeon's experience on the clinical course in patients with a proximal femoral fracture? J Surg Educ. 2018;75(6): 1566-74.

13. AS A. Information about AQC Available at: http://www.aqc.ch/ Willkommen-bei-der-AQC.aspx [Accessed September 27, 2019]

14. Garza MA, Luan J, Blinka M, Farabee-Lewis RI, Neuhaus CE, Zabora JR, et al. A culturally targeted intervention to promote breast cancer screening among low-income women in East Baltimore. Maryland Cancer Control. 2005;12(Suppl 2):34-41.

15. von Holzen U, Gehrz A, Meier L, Zuber M. The AQC database represents a useful tool for quality control and scientific analysis of acute appendicitis. Swiss Med Wkly. 2012;142:w13617.

16. Othmar Schöb TK, Langer I. Fünf fragen an die medizinische qualitätssicherung die selbststeuerung erhalten. Schweizerische Ärztezeitung. 2014;95(39):1146-8.

17. Foundation IFDaPIO. http://www.iofbonehealth.org/data-publi cations [Accessed 27.09.2019]

18. Classification of Diseases F, and Disability. https://www.cdc.gov/ nchs/icd/icd10cm.htm: U.S. Department of Health \& Human Services; [Accesed 28.09.2019]

19. Sektion Gesundheit der Bevölkerung BMK, BFS (2018) Schweizerische Operationsklassifikation (CHOP) Systematisches verzeichnis—version 2018. Bundesamt für Statistik (BFS)

20. Kantonale ethikkommission zürich, stampfenbachstrasse $121 \mathrm{Zr}$. [Authorisation requirements]. Available from: https://kek.zh.ch/ internet/gesundheitsdirektion/kek/de/vorgehen_gesuchseinreich ung/bewilligunspflicht.html.

21. Marcel Graf DOR, Rahel Rüetschli, Stefan Scholz CT, Markus Thomann (2014) Unfallstatistik UVG 2008-2012. SUVA, editor. www.suva.ch: SUVA; 146 
22. Shibuya N, Davis ML, Jupiter DC. Epidemiology of foot and ankle fractures in the United States: an analysis of the National Trauma Data Bank (2007 to 2011). J Foot Ankle Surg. 2014;53(5):606-8.

23. Juto H, Nilsson H, Morberg P. Epidemiology of adult ankle fractures: 1756 cases identified in Norrbotten County during 20092013 and classified according to AO/OTA. BMC Musculoskelet Disord. 2018;19(1):441.

24. Sun Y, Wang H, Tang Y, Zhao H, Qin S, Xu L, et al. Incidence and risk factors for surgical site infection after open reduction and internal fixation of ankle fracture: a retrospective multicenter study. Medicine (Baltimore). 2018;97(7):e9901.

25. Hoiness P, Engebretsen L, Stromsoe K. Soft tissue problems in ankle fractures treated surgically. A prospective study of 154 consecutive closed ankle fractures. Injury. 2003;34(12):928-31.

26. Funke L, Canal C, Ziegenhain F, Pape HC, Neuhaus V. Does the insurance status influence in-hospital outcome? A retrospective assessment in 30,175 surgical trauma patients in Switzerland. Eur J Trauma Emerg Surg. 2021;. https://doi.org/10.1007/ s00068-021-01689-x.

27. Makwana NK, Bhowal B, Harper WM, Hui AW. Conservative versus operative treatment for displaced ankle fractures in patients over 55 years of age. A prospective, randomised study. J Bone Joint Surg Br. 2001;83(4):525-9.

28. Li BH, Wang SX, Li J, Huang FG, Xiang Z, Fang Y, et al. Early and mid-term results of transarticular external fixation in the treatment of supination-external rotation type IV equivalent ankle fractures. Chin J Traumatol. 2018;21(4):193-6.

29. Murray AM, McDonald SE, Archbold P, Crealey GE. Cost description of inpatient treatment for ankle fracture. Injury. 2011;42(11):1226-9.

30. De Boer AS, Schepers T, Panneman MJ, Van Beeck EF, Van Lieshout EM. Health care consumption and costs due to foot and ankle injuries in the Netherlands, 1986-2010. BMC Musculoskelet Disord. 2014;15:128.

31. Per Høiness LE, Strømsøe K. Cost of Surgical Treatment of Closed Ankle Fractures. Eur J Trauma. 2002;28:4

32. Wurdemann FS, Smeeing DPJ, Ferree S, Nawijn F, Verleisdonk $\mathrm{E}$, Leenen LPH, et al. Differentiation in an inclusive trauma system: allocation of lower extremity fractures. World J Emerg Surg. 2018;13:18.

33. Jain NB, Kuye I, Higgins LD, Warner JJ. Surgeon volume is associated with cost and variation in surgical treatment of proximal humeral fractures. Clin Orthop Relat Res. 2013;471(2):655-64.

34. Mufarrih SH, Ghani MOA, Martins RS, Qureshi NQ, Mufarrih SA, Malik AT, et al. Effect of hospital volume on outcomes of total hip arthroplasty: a systematic review and meta-analysis. J Orthop Surg Res. 2019;14(1):468.

35. Metcalfe D, Salim A, Olufajo O, Gabbe B, Zogg C, Harris MB, et al. Hospital case volume and outcomes for proximal femoral fractures in the USA: an observational study. BMJ Open. 2016;6(4):e010743.

36. Pamilo KJ, Peltola M, Paloneva J, Makela K, Hakkinen U, Remes V. Hospital volume affects outcome after total knee arthroplasty. Acta Orthop. 2015;86(1):41-7.

37. Pamilo KJ, Peltola M, Makela K, Hakkinen U, Paloneva J, Remes $\mathrm{V}$. Is hospital volume associated with length of stay, readmissions and reoperations for total hip replacement? A populationbased register analysis of 78 hospitals and 54,505 replacements. Arch Orthop Trauma Surg. 2013;133(12):1747-55.

38. Makela KT, Hakkinen U, Peltola M, Linna M, Kroger H, Remes V. The effect of hospital volume on length of stay, re-admissions, and complications of total hip arthroplasty. Acta Orthop. 2011;82(1):20-6.

39. Lyle SA, Malik C, Oddy MJ. Comparison of locking versus nonlocking plates for distal fibula fractures. J Foot Ankle Surg. 2018;57(4):664-7.

40. SooHoo NF, Krenek L, Eagan MJ, Gurbani B, Ko CY, Zingmond DS. Complication rates following open reduction and internal fixation of ankle fractures. J Bone Joint Surg Am. 2009;91(5):1042-9.

41. Schepers T, Van Lieshout EM, De Vries MR, Van der Elst M. Increased rates of wound complications with locking plates in distal fibular fractures. Injury. 2011;42(10):1125-9.

42. Shen MS, Dodd AC, Lakomkin N, Mousavi I, Bulka C, Jahangir AA, et al. Open treatment of ankle fracture as inpatient increases risk of complication. J Orthop Traumatol. 2017;18(4):431-8.

43. Wijendra A, Alwe R, Lamyman M, Grammatopoulos GA, Kambouroglou G. Low energy open ankle fractures in the elderly: outcome and treatment algorithm. Injury. 2017;48(3):763-9.

44. Anderson KL, Koval KJ, Spratt KF. Hip fracture outcome: is there a "July effect"? Am J Orthop (Belle Mead NJ). 2009;38(12):606-11.

45. Hwang CS, Pagano CR, Wichterman KA, Dunnington GL, Alfrey EJ. Resident versus no resident: a single institutional study on operative complications, mortality, and cost. Surgery. 2008;144(2):339-44.

46. Zafar SN, Shah AA, Hashmi ZG, Efron DT, Haut ER, Schneider $\mathrm{EB}$, et al. Outcomes after emergency general surgery at teaching versus nonteaching hospitals. J Trauma Acute Care Surg. 2015;78(1):69-76 (discussion-7).

47. Walsh AS, Sinclair V, Watmough P, Henderson AA. Ankle fractures: getting it right first time. Foot (Edinb). 2018;34:48-52.

48. Sava J, Kennedy S, Jordan M, Wang D. Does volume matter? The effect of trauma surgeons' caseload on mortality. J Trauma. 2003;54(5):829-33 (discussion 33-4).

49. Wiegers EJA, Sewalt CA, Venema E, Schep NWL, Verhaar JAN, Lingsma HF, et al. The volume-outcome relationship for hip fractures: a systematic review and meta-analysis of 2,023,469 patients. Acta Orthop. 2019;90(1):26-32.

50. Marx WH, Simon R, O’Neill P, Shapiro MJ, Cooper AC, Farrell LS, et al. The relationship between annual hospital volume of trauma patients and in-hospital mortality in New York State. J Trauma. 2011;71(2):339-45 (discussion 45-6).

51. Dumas RP, Seamon MJ, Smith BP, Yang W, Cannon JW, Schwab $\mathrm{CW}$, et al. The epidemiology of emergency department thoracotomy in a statewide trauma system: does center volume matter? J Trauma Acute Care Surg. 2018;85(2):311-7.

52. Amato L, Fusco D, Acampora A, Bontempi K, Rosa AC, Colais $\mathrm{P}$, et al. Volume and health outcomes: evidence from systematic reviews and from evaluation of Italian hospital data. Epidemiol Prev. 2017;41(5-6 (Suppl 2)):1-128. 